\title{
EDITORIAL
}

\section{QUANDO O OBJETO DE ESTUDO É A LITERATURA: ESTUDOS DE REVISÃO}

Um dos grandes desafios de uma profissão é desenvolver um corpo de conhecimento sólido que possa fundamentar e nortear a prática. Com o aumento do número de cursos de pós-graduação e com o estímulo à produção científica, observa-se um crescimento das publicações nas áreas de saúde. Além disso, a implementação da prática baseada em evidências, enquanto uma abordagem para subsidiar decisões clínicas, tem demandado a análise criteriosa da literatura existente. Nesse contexto, estudos que sintetizam a informação científica produzida podem contribuir para o desenvolvimento científico da área, tanto no campo da pesquisa quanto da clínica.

Revisões da literatura são caracterizadas pela análise e pela síntese da informação disponibilizada por todos os estudos relevantes publicados sobre um determinado tema, de forma a resumir o corpo de conhecimento existente e levar a concluir sobre o assunto de interesse ${ }^{1}$. Existem diversos tipos de estudos de revisão e cada um deles segue uma metodologia específica.

Revisão crítica da literatura, também conhecida como estudos de revisão passiva (sintetizam estudos sobre um tema) ou revisões opinativas (analisam a evidência existente sobre um assunto), são estudos nos quais os autores resumem, analisam e sintetizam as informações disponibilizadas na literatura, mas não seguem necessariamente uma metodologia pré-definida. Uma revisão crítica da literatura pode ser desenvolvida sobre temas variados. Muitos periódicos nacionais e internacionais têm adotado a política de publicar esse tipo de artigo de revisão a partir de convites a autores de reconhecida competência no assunto/área.

Por outro lado, estudos de revisão sistemática da literatura e de metanálise adotam uma metodologia padronizada, com procedimentos de busca, seleção e análise bem delineados e claramente definidos, permitindo ao leitor apreciar a qualidade das pesquisas e a validade das conclusões feitas pelos autores. Revisões sistemáticas geralmente utilizam escalas ou formulários que definem critérios que norteiam a apreciação critica da qualidade da evidência científica disponibilizada pelos artigos selecionados. Estudos de metanálise acrescentam a esse procedimento padronizado de análise da evidência, uma síntese quantitativa dos efeitos disponibilizados pelos artigos originais. Tanto a revisão sistemática quanto a metanálise são estudos de revisão que resumem, analisam e sintetizam temas relacionados especificamente a uma intervenção ou protocolo terapêutico. Esses dois tipos de revisão da literatura estão localizados em níveis superiores na hierarquia da evidência científica, comparados com revisões críticas, indicando que os mesmos tendem a apresentar maior rigor metodológico². Conseqüentemente, a revisões sistemáticas e metanálise são geralmente consideradas de melhor qualidade científica e mais conclusivas, quando comparadas com as revisões críticas.

Reconhecendo a importância da síntese da evidência para o desenvolvimento técnico-científico das profissões nas áreas de saúde, a Revista Brasileira de Fisioterapia abre espaço para publicações de estudos de revisão sistemática da literatura e estudos de metanálise. Tal iniciativa visa a contribuir com a idéia de transição de um modelo de prática clínica mais intuitiva para um modelo baseado em evidências. Nesse sentido, destaca-se a importância de os profissionais incorporarem, em seu corpo de conhecimento, os métodos sistemáticos do pensamento e da prática científica.

\section{Marisa Cotta Mancini ${ }^{1}$ \& Rosana Ferreira Sampaio ${ }^{2}$}

\author{
${ }^{1}$ Departamento de Terapia Ocupacional, Programa de Pós-Graduação \\ em Ciências da Reabilitação, EEFFTO, UFMG, Belo Horizonte, MG, Brasil \\ ${ }^{2}$ Departamento de Fisioterapia, Programa de Pós-Graduação \\ em Ciências da Reabilitação, EEFFTO, UFMG, Belo Horizonte, MG, Brasil
}

\footnotetext{
${ }^{1}$ O termo revisão da literatura foi definido por Cooper \& Hedges (1994).

${ }^{2}$ Para maiores informações sobre hierarquia da evidência, ver Ball et al. [online]: http://cebm.jr2.ox.ac.uk/docs/levels.html
} 